\title{
Embalagem de marcas próprias: elementos de semelhança e diferença na construção gráfica
}

\author{
Private labels packing: elements of similarity and \\ difference in construction graphics
}

\begin{abstract}
João Batista Freitas Cardoso I jbfcardoso@uol.com.br Com Pós-Doutorado pela Escola de Comunicação e Artes da Universidade de São Paulo (ECA/ USP), possui doutorado e mestrado em Comunicação e Semiótica pela Pontifícia Universidade Católica de São Paulo (PUC-SP) e graduação em Publicidade e Propaganda pela Universidade Católica de Santos (UNISANTOS). Atualmente é professor titular do Programa de Mestrado em Comunicação da Universidade Municipal de São Caetano do Sul (PPGCom/USCS) e professor nas universidades Mackenzie e Santa Cecília.

Thiago Bertoldo I thiago_bertoldo@yahoo.com.br Designer e consultor de marketing, mestre em Comunicação pela USCS, especialista em Marketing pela UNAERP e graduado em Design pela Universidade São Judas Tadeu. Atualmente, é diretor da Oficina B! (escritório especializado em design) além de lecionar em instituições de ensino superior nas áreas de Publicidade, Design, Marketing e Administração.
\end{abstract}

\section{Resumo}

O texto propõe a discussão sobre como o design de embalagem contribui para construção da identidade de um produto no segmento de marca própria. Para isso, foi realizada uma análise comparativa entre embalagens de produtos da marca Qualitá e embalagens de marcas líderes, em que se verificou que as primeiras utilizam estratégias de semelhança e diferenciação para criar sua identidade

Palavras-Chave: Embalagem; Marca Própria; Composição Visual.

\begin{abstract}
The text proposes a discussion on how packaging design contributes to building the identity of a product in the private label segment. For this, we performed a comparative analysis of packaging products and packaging brand Qualita leading brands, it was found that the first use of similarity and differentiation strategies to create its identity.
\end{abstract}

Keywords: Packing; Private Labels; Visual Composition. 


\section{Introdução}

Vivemos em uma sociedade dinâmica, instável e em constante evolução. As causas da globalização afetam nossas vidas e praticamente todos os ramos de negócios enfrentam os efeitos competitivos globais. As inovaçóes tecnológicas são rapidamente lançadas no mercado e empresas que não conseguem transmitir em seus produtos ou serviços diferenciais competitivos passam a brigar com seus concorrentes apenas na política de preço.

Diante desse cenário, as marcas vêm se revelando como o maior patrimônio das empresas, pois é através delas que as empresas passam valores a seu público. Adotar uma marca implica proteger um produto ou um serviço contra possíveis imitaçóes, além de criar identidade e diferenciação no ponto de venda. Isso acaba também por estimular a recompra e permite o desenvolvimento de extensóes de linhas de produtos.

As influências da marca, bem como suas possibilidades de atuação, dependem diretamente da estratégia administrativa e comercial adotada pela empresa, que controla e define as características mais adequadas para sua apresentação no mercado e para a venda do seu negócio. Assim, pela maneira como a estratégia é conduzida, a imagem da marca pode gerar atribuições que vão além das expectativas tanto do mercado, quanto dos consumidores. Isso dependerá, entretanto, de como a imagem da marca será assimilada pelo consumidor, bem como da abordagem utilizada pela concorrência na construção de sua imagem de marca.

Marcos Gouvêa de Souza e Artur Nemer (1993, p. 6) consideram como princípios básicos de atuaçáo das marcas registradas: distinguir os produtos e serviços de uma empresa; indicar a fonte ou origem de produtos e serviços; representar o valor intrínseco da empresa proprietária da marca registrada; e servir como indicativo de qualidade de seus produtos e serviços.

Esses aspectos definem, de uma maneira ou de outra, a imagem das marcas. Essa imagem, para Marty Neumeier (2008, p. 15), está associada também a uma percepçáo íntima e a um sentimento que a pessoa pode ter em relaçáo a um produto ou a um serviço. Ela é definida, então, por pessoas e não por empresas ou pelo mercado, pois são essas que criam a própria versão da marca.

Neumeier afirma que, quando um número satisfatório de pessoas atinge o mesmo sentimento em relação a uma marca, aí sim podemos dizer que a empresa realmente possui uma marca. Assim, surge o que comumente chamamos de valor de marca. $\mathrm{O}$ valor da marca, nesse sentido, está diretamente relacionado à qualidade percebida, que nada mais é do que um conhecimento, transformado em valor, que é relacionado ao produto. $\mathrm{O}$ conceito de qualidade, nesse caso, difere de uma satisfação ou atitude positiva percebida. Ele está relacionado a um sentimento geral sobre a marca, baseado em dimensóes às quais a marca esteja conectada, como: características de produto, performance e confiança.

Há sérios problemas com a resposta kantiana à questão epistemológica que ele mesmo formulou: "o que posso saber?". Mas não nos cabe aqui aprofundar a crítica sobre o modelo kantiano. Sua filosofia nos interessa na medida em que sua formulaçáo determinou o modo como se discutiria epistemologia a partir de então. 
Há um pressuposto em Kant que devemos abordar se quisermos compreender o papel importante da reflexáo epistemológica na comunicaçáo e, para tanto, precisamos recuperar a distinção cartesiana entre res cogitans e res extensa (dualismo) e, em seu desdobramento, as conclusóes que Newton retira desta separação.

O conceito de Brand Equity, definido por David Aaker (2001, p. 16), se tornou uma constante temática na estrutura das organizaçóes, pois é responsável por transformar os valores intangíveis das empresas em ativos. Como constituintes do valor da marca, Aaker aponta cinco categorias de ativos: lealdade à marca, conhecimento do nome, qualidade percebida, associaçóes à marca em acréscimo à qualidade e outros ativos proprietários da marca como patentes e trademarks.

Observando algumas associaçôes de marca existentes no mercado, pode-se afirmar que elas dependem direta e indiretamente da estratégia de posicionamento adotada pela empresa. Diretamente, no caso de a empresa definir e priorizar os elementos considerados chave, que serão responsáveis pela ligaçáo com a imagem da marca, realizando esses objetivos através das açóes de marketing e comunicação. Indiretamente, em função da maneira como a comunicação será compreendida pelo público e manifestada no comportamento de compra e fidelidade à marca. Elementos emocionais agregados ao posicionamento, por meio do design, publicidade ou eventos promocionais, agregam ao produto qualidades que vão além de suas características tangíveis.

Para Clotilde Perez (2004, p. 113), para agregar valor à marca é preciso não só cuidar da melhoria da qualidade dos produtos, mas também alterar a percepção do consumidor. Para isso, a empresa deve investir em aspectos inovatórios relacionados ao design. Nesse sentido, um novo design de embalagem pode significar uma mudança na imagem do produto, além de influenciar na solidez de uma marca. Através do design, podemos conferir personalidade a uma marca.

Entendendo que a imagem da marca está relacionada diretamente à identidade de seus produtos, o presente artigo objetiva discutir como o design de embalagem pode contribuir para construção da identidade de um produto no segmento de marca própria, fazendo com que esta se diferencie da concorrência. Para alcançar esse objetivo, foi realizada uma análise comparativa entre duas embalagens de produtos de diferentes segmentos da marca Qualitá - marca própria da Companhia Brasileira de Distribuição (CDB), detentora das marcas Pão de Açúcar, Extra, Compre Bem, Sendas, Assaí e Ponto Frio - e duas embalagens de marcas líderes nesses segmentos, onde se verificou que as embalagens de produtos de marca própria utilizam de estratégias de semelhança e diferenciação - no que se refere aos elementos visuais de composição do invólucro e do rótulo - em relação à concorrência para criar uma identidade própria.

\section{Design e identidade}

Para agregar valor ao produto é preciso não apenas cuidar da melhoria da qualidade, mas também alterar a percepção do consumidor (PEREZ, 2004, p. 113). Para isso, a empresa deve investir em aspectos 
inovatórios relacionados ao design. Um novo design de embalagem pode significar uma mudança na imagem do produto, além de influenciar na solidez da marca. Através do design é possível conferir personalidade a uma marca própria, evitando que o consumidor a confunda com outras marcas que pertencem à mesma categoria.

Quando o design de uma marca é concebido, tanto os valores emocionais quanto os aspectos tangíveis devem ser considerados na composição da representação visual que irá defini-la. No que se refere aos valores emocionais, acredita-se que esses são os principais responsáveis por atribuir confiabilidade aos produtos. O branding, que pode ser considerado um procedimento de açóes interdisciplinares que visa a consolidar a imagem da marca, é um dos principais elementos na criação de vínculos emocionais entre as marcas e seus consumidores.

Entre os procedimentos de branding, encontra-se a construção de uma identidade própria para a marca. Essa identidade, sob o ponto de vista da comunicação visual, é estabelecida em função da relação entre um conjunto sistematizado de diversos elementos gráficos - logotipo, símbolo gráfico, conjunto tipográfico, cores etc. - que irão formalizar a personalidade visual de uma empresa, instituição, produto ou serviço. É fundamental para o sucesso das marcas apresentarem identidades visuais consistentes, que propiciem seu efeito acumulativo (STRUNCK, 2003, p. 57).

Para Lynn B. Upshaw (1995, p.12-13), o conceito de identidade de marca é a impressão digital única que torna a marca diferenciada. Ela é o modo como a empresa demonstra sua personalidade estratégica, que torna mais humanos todos os elementos de execução tangíveis e intangíveis, bem como os aspectos físicos da marca, como seu nome e representação gráfica. É uma identificação própria, em que a marca tem características físicas e intangíveis que a tornam única, exclusiva e, a priori, distinta das demais existentes. No sistema de identidade proposto por Upshaw (1995, p. 24), um dos pontos que se relacionam com a "essência da marca" é o sistema gráfico. Esse sistema gráfico está relacionado ao processo de construção do Trade Dress.

\section{Trade Dress e semelhança}

A construção da identidade de uma marca passa, obrigatoriamente, pela definição de sua identidade visual. Sob esse ponto de vista, Trade Dress pode ser definido como uma forma de apresentação, composta principalmente por elementos visuais, que permite ao consumidor identificar a origem do produto ou serviço pela marca apontada.

Consiste num conjunto de caracteristicas, que pode incluir, entre outras, uma cor ou esquema de cores, forma, embalagem, configuração do produto, sinais, frases, disposição, estilização e tamanho de letras, gráficos, desenhos, emblemas, brasóes, texturas e enfeites ou ornamentos, capazes de identificar determinado produto ou diferenciá-lo dos demais (DANIEL, 2006, p. 1). 
Contudo, ainda que o Trade Dress de um produto ou serviço seja uma forma de apresentação única e distintiva, é certo que algumas características que guardam relação com um produto ou serviço podem ser encontradas em todos os Trade Dresses de um determinado segmento de mercado e, por consequência, venham a ser consideradas como códigos de categoria. Para Rafael Cardoso, certas semelhanças podem ser consideradas características formais significativas:

Em se tratando de garrafas d'água, fica evidente a ligação conceitual entre a transparência da embalagem e a idéia de pureza. Por experiência associamos água limpida água limpa. Motivado por uma associação tão forte e essencial, era de se esperar que todas as garrafas d'água fossem transparentes (2012, p. 129).

Nesse caso, tais códigos não podem ser considerados exclusivos a uma marca do segmento. Os códigos de categoria têm maior abrangência e podem conter características que não tenham relação exclusiva com uma determinada marca como, por exemplo, o amarelo usado nos tubos de mostarda ou o vermelho usado nas caixas de molho de tomate. São justamente esses códigos que permitem ao consumidor diferenciar, em um mercado, a "gôndola de bebidas" da "gôndola de condimentos". Partindo desse pressuposto, no desenvolvimento do projeto de embalagem, o designer deve compreender a categoria em que o produto compete, para evitar que o consumidor confunda seu produto com algo que ele não é, ou, ainda mais grave, que ele não seja considerado na hora da compra de um produto da categoria em que ele compete.

Ainda que se deva considerar a linguagem da categoria, que parte do princípio de que determinados códigos devem ser compartilhados, algumas empresas fazem uso da estratégia de semelhança no design da embalagem de seus produtos, reproduzindo apenas os principais elementos que compóem o Trade Dress de um concorrente. Esgueirando-se da evidente prática de falsificação dos signos distintivos de uma dada marca, essas empresas muitas vezes conseguem incrustar na mente do consumidor uma grande proximidade entre o conjunto imagem original, do corrente, e o conjunto imagem contrafeito. Para Lucas Bernardo Antoniazzi (2010, p. 10), a violação do Trade Dress:

Ocorre quando determinada apresentação visual é copiada por um terceiro que, reproduzindo ou imitando tal signo distintivo, visa a confundir o consumidor para que este consuma os seus serviços/produtos, em substituição dos serviços/produtos do titular do trade dress original. Com isso, ele consegue ingressar em determinado segmentado mercadológico, ou expandir a comercialização de seus produtos ou serviços.

Segundo Cardoso (2012, p. 127-128), é a partir da comparação entre as semelhanças plásticas que é aplicada a lei de propriedade intelectual relacionada ao campo do desenho industrial. No entanto, nem sempre a infração de Trade Dress irá se apresentar de forma tâo óbvia como a cópia exata do Trade Dress original. A forma mais sutil para levar o consumidor ao erro é por meio da reprodução de 
alguns dos principais elementos que compóem o conjunto imagem de determinado produto. Nesse caso, o Trade Dress imitado é suficientemente distinto do original para eliminar qualquer chance de ser considerado uma cópia exata.

Por meio da cópia das principais características que compóem o Trade Dress original, a marca demonstra ao público consumidor que o seu produto/serviço apresenta as mesmas qualidades, funçóes ou características e propriedades que o produto/serviço trazido pelo Trade Dress original. Assim, ao contrário da cópia do conjunto completo da imagem original, entende-se que a cópia apenas dos principais elementos visuais importaria em uma reprodução subjetiva, que pretende levar o consumidor a realizar associaçôes indevidas entre os produtos/serviços em cotejo (ANTONIAZZI, 2010, p. 12).

No que se refere às práticas imitativas, segundo Gino Giacomini Filho (2011, p. 220), essas estão relacionadas diretamente a dois princípios básicos da gestalt: o da semelhança e o da proximidade. Ao se transportar tais princípios para o campo do design de embalagem, em particular, é possível observar que a semelhança pode envolver a imitação de um ou mais elementos gráficos (forma, imagem, cor, tipografia) ou o conjunto estético como um todo (padrão gráfico, identidade visual, associaçóes de elementos). No caso das práticas imitativas, os elementos gráficos são tomados em conjunto pela similaridade e aproximação entre eles. Quando se aborda a imitação de peças publicitárias, geralmente as análises e decisóes repousam não em cima de um único elemento estético, mas sobre um conjunto desses (GIACOMINI FILHO, 2011, p. 220). O mesmo acontece no campo das embalagens.

\section{Marcas próprias e identidade}

As marcas próprias são as únicas marcas pelas quais o varejo deve se responsabilizar pelo gerenciamento total, desde o desenvolvimento até a comercializaçáo e promoção (DHARE; HOCH, apud UNTERLEIDER; DAMACENA 2006, p. 65). Nesse sentido, apresentam-se como um produto exclusivo do canal. O signo de marcas próprias serve para fidelizar e difundir a imagem da loja, enfatizando seu potencial comunicativo e atuando, assim, como ferramenta de comunicação no próprio ponto de venda (MOREIRA, 2010, p. 23).

Sob o ponto de vista mercadológico, Clotilde Perez (2004, p. 18) destaca algumas estratégias básicas de utilização da marca: Marcas guarda-chuva - geralmente empregada por empresas que atuam em mais de um segmento de mercado; Marcas individuais - com identidade própria para cada produto; Marcas mistas - objetivam personalizar um produto sem abandonar aspectos positivos, especialmente os de credibilidade e confiança, da imagem da sua marca guarda-chuva ou marca mãe; Extensão de marcas - aplicando a estratégia de extensão, a empresa pretende criar uma 
transferência de valores da marca de um produto para outros que lançar, de características diferentes, ampliando a custo baixo, às opçóes de oferta no mercado, aproveitados da imagem da "marca-mãe".

Relacionando-se as definiçôes propostas por Perez às marcas próprias, e considerando, a grosso modo, que marcas próprias são marcas sob licenciamento exclusivo de uma empresa varejista que atua em mais de um segmento de mercado, com produtos de diferentes linhas que compartilham o mesmo nome e atributos de imagem, pode-se afirmar que toda marca própria pode ser considerada uma marca "guarda-chuva".

Apesar dos produtos de marca própria, a princípio, terem seu reconhecimento apenas como uma alternativa a custo baixo perante as marcas líderes, os produtos que compóem esse tipo de categoria podem se diferenciar dos concorrentes em uma série de aspectos. Ao perceberem que os consumidores se tornaram mais exigentes, atribuindo valores aos produtos que têm um melhor design (MESTRINER, 2002, p. 29), as redes varejistas passaram a investir mais nesses aspectos, estabelecendo relaçóes de semelhança com as marcas líderes, para que seus produtos apropriem-se de determinadas qualidades das imagens dessas, e relaçóes de contrastes com esses concorrentes, para que o portfólio de produtos da marca colabore na construçáo de uma identidade própria para a marca.

Nesse processo de construção da marca, relaçôes de semelhanças e contrastes são estabelecidas entre os elementos visuais gráficos impressos - figuras, tipografia, cores, texturas e composição - e os elementos visuais de composição do invólucro - material, forma e direção.

$\mathrm{Na}$ análise comparativa realizada entre produtos da marca Qualitá e seus concorrentes - no segmento de batatas e cremes de leite - foram observados tantos os elementos gráficos impressos como os elementos de composição do invólucro. A escolha da marca Qualitá como objeto de análise se deu pelo fato de esta pertencer a $\mathrm{CDB}$, maior rede supermercadista brasileira segundo o ranking supermercadista da Associação Brasileira de Supermercados (ABRAS, 2011), e conter ainda a maior variedade de produtos e assumir o posicionamento de marca de combate, para "brigar" por preço com as marcas líderes de cada categoria. A opção pela análise das embalagens de creme de leite e DE batata se deu em função da variedade de elementos gráficos utilizados no design dessas embalagens, o que permite fazer uma análise comparativa mais completa.

\section{Creme de leite Qualitá e Nestlé: predomínio das semelhanças}

Observando o segmento de cremes de leite, percebe-se que tanto o produto da Qualitá quanto o da Nestlé, líder no segmento, utilizam o mesmo formato e tipo de material na embalagem e no rótulo. Para Mestriner, "novos materiais, processos de rotulagem, sistemas de abertura, de dosagem, de exposição, são diferenciais de impacto ao consumidor" (2002, p. 23). Contudo, o aproveitamento do mesmo tipo de embalagem, nesse caso, está associado diretamente à questão do custo de produção. Utilizar a mesma embalagem reduz o custo no processo de envase, transporte e armazenamento do produto. 

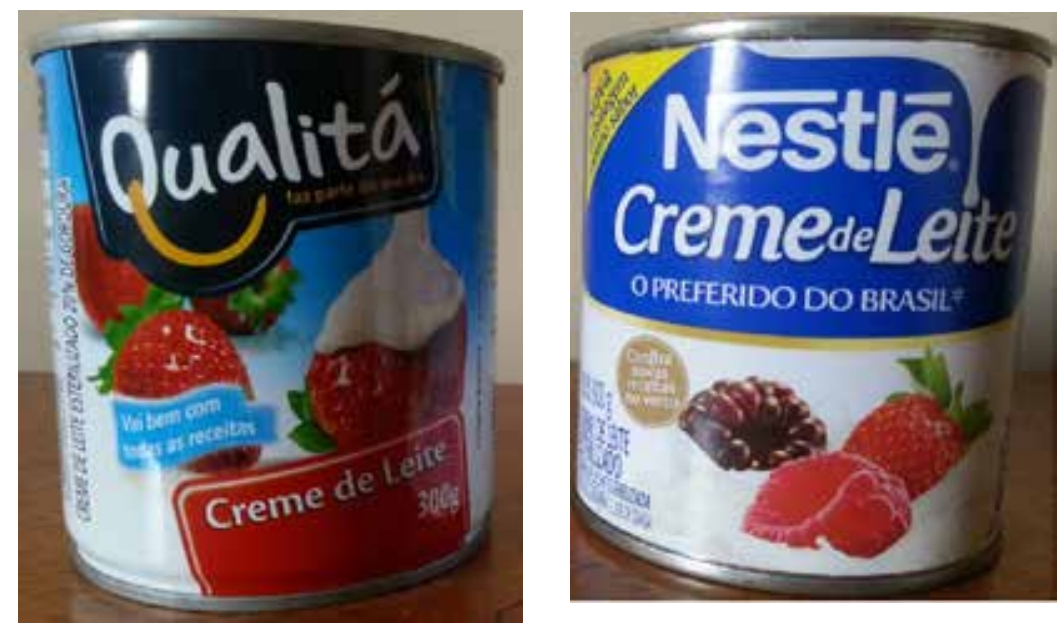

Fig. 1: Latas de creme de leite Qualitá e Nestlé. Fonte: arquivo pessoal.

Analisando o fundo do rótulo, percebe-se que predominam nas duas embalagens as cores branca e azul. A princípio, essas cores apresentam-se como convenção da categoria. Ou seja, os cremes de leite de outras marcas também fazem uso das mesmas cores. Isso porque o branco estabelece uma relação de semelhança com a cor do próprio produto, o creme, e o azul é uma convenção nos segmentos de produtos lácteos. Nos termos de Charles S. Peirce (2003), o reconhecimento da semelhança entre dois elementos se dá em função do caráter icônico do signo, já a compreensão de uma convenção se deve à natureza do legi-signo, signo esse que se apresenta como uma lei.

Ainda que, sob a ótica da semiótica peirciana, se considere o aspecto icônico da cor branca, a própria combinação de cores apresenta-se também como um legi-signo, uma convenção nesse segmento de produto. Em outros termos, uma convenção seguida pelos designers no momento na definição de cores do fundo que visa a levar o consumidor ao reconhecimento do tipo de produto.

Contudo, ainda que as semelhanças entre as duas embalagens sejam maiores, os fundos se diferenciam na maneira como as cores são delimitadas. Na embalagem da Nestlé, há a presença de uma clara divisão das cores e a presença da cor dourada, já na Qualitá os limites são imprecisos, em virtude da fusão entre as duas cores. A cor dourada na Nestlé, em particular, sugere glamour e fama como qualidades percebidas (BASTOS, FARINA, PEREZ, 2006, p. 107), além de dar ao produto a chancela de uma marca de forte presença no mercado.

As linhas curvas e formas orgânicas - nos boxes, splashs, fontes e formas figurativas - também se apresentam como elementos de semelhança entre as embalagens. Essas formas impregnam a embalagem de movimento e delicadeza, atribuindo ao produto qualidades de cremosidade e leveza, que são fundamentais nesse tipo de produto.

Com relação aos aspectos figurativos, ambas as embalagens apresentam representaçóes de frutas em contato com o produto - na embalagem da Qualitá a representação de morangos e na da Nestlé frutas do grupo conhecido como "frutas vermelhas". Esse tipo de representação também se apresenta como uma linguagem da categoria, como legi-signo. Tal signo tem os seguintes objetivos: apresentar o produto que está na embalagem, apresentar a forma de consumo do produto e gerar desejo. 
Nos dois primeiros casos, a convenção tem, nos termos de Peirce, um caráter indicativo, que objetiva principalmente levar ao reconhecimento. $\mathrm{O}$ consumidor deve saber o que é e para que serve o produto. Já no terceiro, a convenção serve para estimular o desejo, trabalha com as sensaçóes. Esse aspecto qualitativo do signo em muito se deve aos seguintes elementos: cores, formas, movimento e textura das representações visuais. É justamente o uso desses elementos básicos na composição que torna a representação do produto "gostosa", que evidencia o appetite appeal. Segundo Mestriner, "o conceito de appetite appeal é um marco na construção da linguagem da embalagem, pois estabelece intencionalmente uma reação provocada no desejo do consumidor" (2002, p. 16).

Com isso, se conclui que apesar de algumas diferenças pontuais entre as embalagens, devido aos traços de semelhança, elas são muito parecidas. Isso é percebido pelas cores, pela forma que o fundo da embalagem se divide, pela sugestão de consumo que elas apresentam e pelas imagens que elas trazem, evidenciando o appetite appeal. Dessa forma, essa configuração se torna comum aos olhos dos consumidores e permite que possamos entender que os valores trazidos em uma embalagem são muito similares na outra.

\section{Batatas Qualitá e Ruffles: predomínio do contraste}

Quando observamos as embalagens no segmento de batatas fritas, as diferenças se tornam mais proeminentes. Ainda que tanto o produto da Qualitá quanto o da Ruffles utilizem embalagens com o mesmo formato, desenvolvidas com o mesmo material, ao analisar os fundos impressos em ambas facilmente se percebem as diferenças. Enquanto na Qualitá o alumínio é importante para manutenção da identidade, na Ruffles predomina o azul.
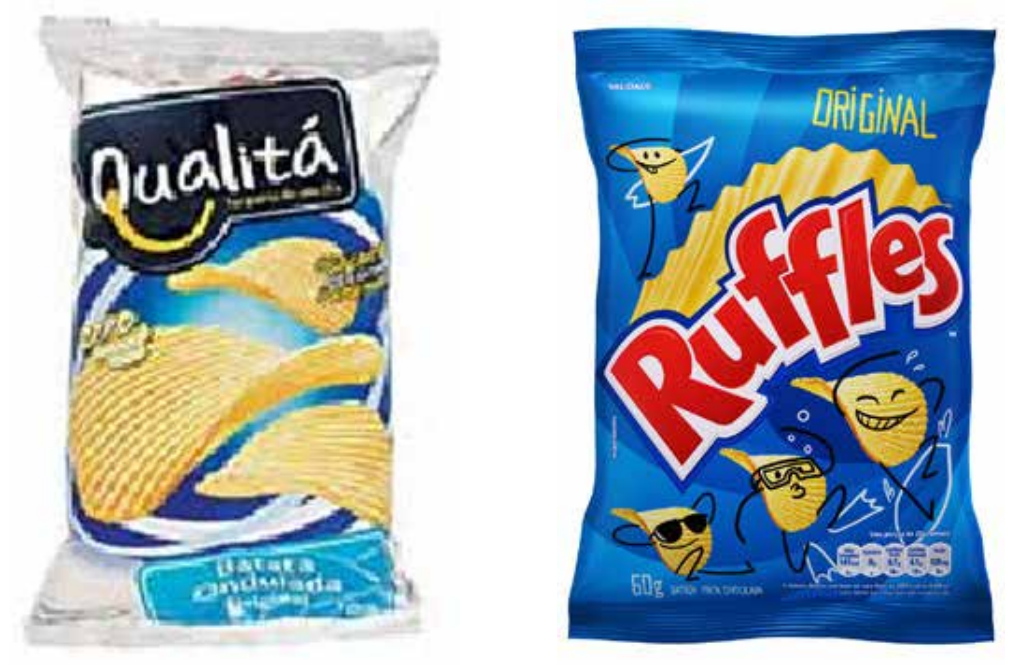

Fig. 2 - Batata ondulada Qualitá (dir.) e batata Ruffles (esq.). Fonte: arquivo pessoal.

Ao contrário das diferenças observadas em relação às cores dos fundos das duas embalagens, as linhas curvas e formas orgânicas apresentam-se como elementos de semelhança entre as embalagens. Em ambas há o predomínio de formas redondas e circulares, além dos grafismos de ambas também assumirem movimentos curvos e circulares, dando a impressão, em um primeiro contato, que há uma interação entre eles. 
Com relação aos aspectos figurativos, as duas embalagens apresentam representaçôes do produto em si. No caso da Ruffles, no entanto, as imagens das batatas se apresentam com feições humanizadas. Elas aparecem praticando esportes como surfe, mergulho ou até mesmo tomando sol. Assim, acabam propondo um convite ao observador para que ele interaja, sugerindo a eles que pratiquem as atividades sugeridas pelas figuras. Além disso, essas imagens se tornam a identidade promocional do produto, que tem como finalidade a aproximação com o consumidor (MESTRINER, 2002, p.95).

$\mathrm{Na}$ embalagem das batatas Ruffles, o efeito do appettite appeal, citado na análise do creme de leite, não fica tão evidente, já que o produto humanizado faz com que as qualidades relacionadas ao paladar não sejam tão exploradas. As figuras das batatas, nesse caso, representam a imagem do produto associada ao perfil de seu público. $\mathrm{Na}$ Qualitá, ao contrário, a textura, dimensão e movimento em direção ao observador valorizam suas qualidades palatáveis.

Ainda que se observem esses aspectos distintos, ambas as imagens presentes nas embalagens são ricas em termos singulares-indicativos, ao demonstrarem o produto que está na embalagem, e apresentam-se também como linguagem da categoria. Temos, assim, uma convenção que tem um caráter indicativo com o objetivo de levar ao reconhecimento. O consumidor deve saber qual é o tipo de produto no interior das embalagens.

Ao realizar essa análise, o que se pode perceber é que tudo indica que a estratégia adotada pela Qualitá é a de criar uma linguagem própria para sua categoria de produtos no segmento de batatas, reforçando assim o reconhecimento do produto e por consequência, da marca.

\section{Considerações finais}

Quando levamos em conta o composto do Trade Dress para a criação de uma identidade marcaria, entendemos que esse conjunto imagem serve para conferir ao produto uma identidade, isto é, traz ao produto uma personalidade que se reflete diretamente no seu reconhecimento e geraçáo de valor pelo consumidor. É através dele que o observador consegue reconhecer um determinado produto e diferenciá-lo dos concorrentes.

Para promover os lançamentos, ao contrário das grandes marcas com as quais competem, os produtos de marca própria não contam com publicidade e precisam investir em ações estratégicas de ponto de venda e gôndolas através de suas embalagens (MESTRINER, 2002, p. 43). Várias estratégias de posicionamento relacionadas às marcas próprias aparecem a todo o momento para diferenciá-las das concorrentes e buscarem valor.

Uma das estratégias que merece destaque é o posicionamento fantasia. Essa estratégia visa a trazer ao consumidor um conceito de inovaçáo e confere às marcas próprias um valor agregado que motiva os consumidores a adquirir esses produtos, que na sua visão, têm mais qualidade, gerando assim um valor maior de vendas e lucros. Com o passar do tempo, algumas marcas próprias, objetivando alcançar posiçóes mercadológicas, assim como as marcas líderes, começaram a utilizar 
elementos presentes nas marcas líderes para gerar identidade junto aos consumidores. Isto é, dentro do seu Trade Dress, alguns elementos gráficos presentes nas marcas líderes começam a aparecer nas marcas próprias.

Nas análises apresentadas, verificamos que tanto a estratégia de semelhança quanto a estratégia de diferenciação são utilizadas pelas marcas próprias. No caso da embalagem de creme de leite, verificou-se no produto da Qualitá a presença de elementos visuais semelhantes aos utilizados no produto da marca líder, Nestlé. Essas semelhanças permitem afirmar que os valores explorados pela marca líder acabam sendo apropriados pela marca própria. $\mathrm{Na}$ análise das batatas fritas, ao contrário, a estratégia adotada pela marca própria é se diferenciar da estratégia adotada pela marca líder, Ruffles, o que faz com que a primeira construa uma identidade própria.

Ao observarmos os aspectos de semelhança entre os produtos de uma mesma linha da marca Qualitá, percebemos que a estratégia de construçáo de uma identidade própria se fortalece. Tanto no segmento de batatas (Figura 3) quanto no segmento de biscoitos (Figura 4), a estratégica adotada pela marca Qualitá é a de criação de uma identidade para cada categoria de produtos. Forma e material dos invólucros, tipografias, cores, figuras e composição mantém uma unidade visual. A estratégia também é utilizada pelas marcas líderes.
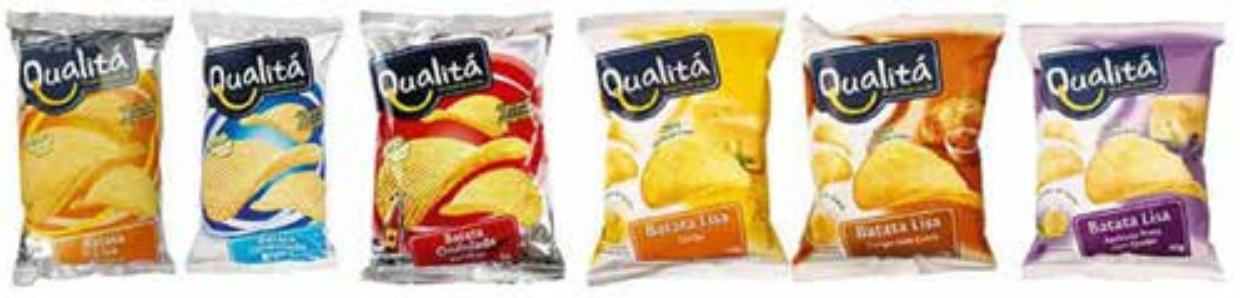

Fig. 3 - Batatas variadas Qualitá. Fonte: arquivo pessoal.

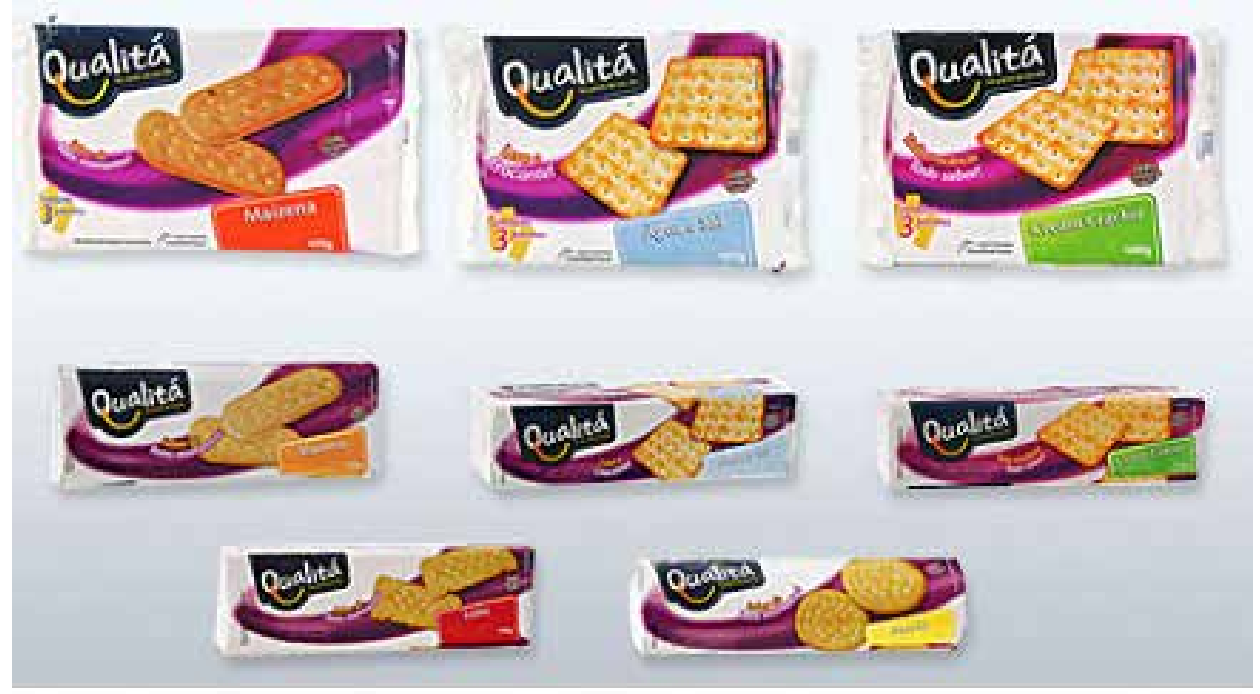

Fig. 4 - Biscoitos variados Qualitá. Fonte: arquivo pessoal.

Ainda que se perceba que as marcas próprias investem em design para obter diferenciação frente aos seus concorrentes, elas também fazem uso de elementos presentes em marcas de grande representatividade no mercado ou de 
algum tipo de estratégia adotada por essas. Assim, fica evidente que a marca própria, por mais que tenha a força da marca mãe, necessita se escorar em marcas de maior representatividade mercadológica para obter a atenção do consumidor. Deve, como as outras marcas, seguir a linguagem da categoria.

\section{Referências Bibliográficas}

ABMAPRO. Disponível em: <http://www.abmapro.org.br/page/marcapropria_panorama.asp.>. Acesso em 28 abr. 2011.

AAKER, David A. Marcas - brand equity: gerenciando o valor da marca. 2a ed. São Paulo: Negócio, 2001.

ANTONIAZZI, Lucas Bernardo. Trade Dress e concorrência desleal: o sistema legal de vedação à concorrência é suficiente para garantir a proteção desse instituto? Algumas observaçôes e sugestôes. Coordenação central de extensão programa pós graduação. PUC Rio. Rio de Janeiro, 2010.

BASTOS, Dorinho, FARINA, Modesto, PEREZ, Clotilde. Psicodinâmica das cores em comunicação. 5a ed. São Paulo: Edgar Blucher, 2006.

CARDOSO, Rafael. Design para um mundo complexo. São Paulo: Cosac Naify, 2012.

DANIEL, Denis Allan. Litígio envolvendo conjunto-imagem (Trade Dress) no Brasil: a área nebulosa de proteção da propriedade intelectual. Disponível em: http://www.daniel.adv.br/port/articlesPublications/denisDaniel/TRADE_DRESS.pdf; 2006.

GIACOMINI FILHO, Gino. Tipologias de imitação estética na propaganda. Matrizes, vol. 4, n.2, 2011.

MESTRINER, Fábio. Design de Embalagem - Curso Avançado. São Paulo: Makron Books, 2002.

MOREIRA, Rogério Bandeira de Melo. Construção das marcas próprias Taeq, Qualitá e Dia a partir do estudo dos contratos de comunicação. 115 fls., Dissertação. Programa de Mestrado em Comunicação e Semiótica da Pontifícia Universidade Católica de São Paulo (COS/PUC-SP), 2010.

NEUMEIER, Marty. The Brand Gap: O Abismo da Marca. 2a Ed. Rio Grande do Sul: Bookman, 2008.

PEIRCE, Charles S. Semiótica. São Paulo: Perspectiva, 2000.

PEREZ, Clotilde. Signos da Marca. São Paulo: Pioneira Thomson Learning, 2004.

SOUZA, Marcos Gouvêa de e NEMER Artur. Marca \& Distribuição - Desenvolvendo dominação estratégica e vantagem competitiva no mercado global. São Paulo: Makron Books, 1993.

STRUNCK, Gilberto. Como criar identidades visuais para marcas de sucesso. São Paulo: Rio Books, 2003. 
UNTERLEIDER, Jorge Antônio Apollo; DAMACENA, Claudio. Estratégias de desenvolvimento de marcas próprias por supermercados no Brasil. Revista de administração Mackenzie, Vol. 7, n.3, 2006.

UPSHAW, Lynn B. Build Brand Identity - A Strategy for sucess in a hotstile marketplace. Wiley \& Sons, Inc., 1995. 